Canadian Journal of Higher Education Revue canadienne d'enseignement supérieur

Volume 46, No. 4, 2016, pages 76 - 93

\title{
Sustainable Implementation of Interprofes- sional Education Using an Adoption Model Framework
}

Ruby E. Grymonpre, Christine A. Ateah, Heather J. Dean, Tuula I. Heinonen, Maxine E. Holmqvist, Laura L. MacDonald, A. Elizabeth Ready, and Pamela F. Wener University of Manitoba

\begin{abstract}
Interprofessional education (IPE) is a growing focus for educators in health professional academic programs. Recommendations to successfully implement IPE are emerging in the literature, but there remains a dearth of evidence informing the bigger challenges of sustainability and scalability. Transformation to interprofessional education for collaborative person-centred practice (IECPCP) is complex and requires "harmonization of motivations" within and between academia, governments, healthcare delivery sectors, and consumers. The main lesson learned at the University of Manitoba was the value of using a formal implementation framework to guide its work. This framework identifies key factors that must be addressed at the micro, meso, and macro levels and emphasizes that interventions occurring only at any single level will likely not lead to sustainable change. This paper describes lessons learned when using the framework and offers recommendations to support other institutions in their efforts to enable the roll out and integration of IECPCP.
\end{abstract}

\section{Résumé}

L'éducation interprofessionnelle (EIP) fait l'objet d'un intérêt grandissant parmi les enseignants des programmes universitaires pour professionnels de la santé. Bien que des recommandations pour une mise en œuvre réussie de l'EIP fassent leur apparition dans les publications académiques, il existe encore un manque de données probantes sur les défis plus importants que représentent la durabilité et la modularité. La transformation de l'EIP vers une pratique interprofessionnelle et collaborative axée sur la personne (PPCAP) est complexe et nécessite l' « harmonisation des motivations » entre différents secteurs (universitaire, gouvernemental, des soins de la santé et de la consommation), et au sein de ceux-ci. La principale leçon qu'a reçue l'Université du Manitoba a été la nécessité d'employer une structure 
formelle de mise en place pour diriger ses travaux. Cette structure identifie les caractéristiques essentielles que l'on doit aborder à petite, moyenne et grande échelle et souligne l'importance de ces interventions à plusieurs niveaux, sans quoi le changement n'est pas durable. Cet article décrit les leçons apprises avec la structure et propose des recommandations afin d'aider d'autres institutions dans leurs efforts de création et d’intégration de la PPCAP.

Effective change management requires synchronized efforts at different levels: (1) the individuals carrying out the vision towards change, (2) the teams of individuals working together to drive the culture, and (3) the systems level transformation to motivate and guide groups to permit certain types of behavior and encourage the formation of commitment to change. (Borduas et al., 2006, p. 16).

The overall goal of interprofessional education for collaborative person-centred practice (IECPCP) is to modify behaviours and ways of working together to improve healthcare outcomes, service efficiency, cost-effectiveness, and staff satisfaction. Transformation from conventional health service delivery models to IECPCP is complex and requires "harmonization of motivations" within and between academia, governments, healthcare delivery sectors, and consumers (Borduas et al., 2006, p. 16). To support these changes, interprofessional education (IPE) brings together trainees from different health professions to learn with, from, and about each other (CAIPE, 2002). Despite widespread support for the idea of integrating IPE into the training of health professionals, there is little information available about the best way to effect these curricular changes. When an organization is considering adoption, assimilation, and implementation of an innovation such as IPE, Borduas et al. (2006) have suggested the use of an adoption model to provide guidance to organizational change. Adoption models draw attention to the complex attributes, processes, and interactions between the innovation and its users, communication and its influence, as well as internal and external contexts (Greenhalgh, Robert, Macfarlane, Bate, \& Kyriakidou, 2004). More specifically, Borduas et al. (2006) recommended examining the adoption of IPE within higher education institutions using a change management or adoption framework such as Greenhalgh's Diffusion of Innovations in Service Organizations. Clark (2013) proposed the Transtheoretical Model of Institutional Change, as it acknowledges the complexity of change, and it identifies important theoretical elements, developmental processes, and forces, as well as readiness and strategies of change. Further, Borduas et al. (2006) pointed out that the use of such adoption model frameworks to facilitate the diffusion of IPE within higher education institutions appears to be lacking in the literature.

Despite the mounting literature describing IPE innovations, recommendations for successful implementation are inconsistent across studies. Studies examining IPE implementation often include the importance of leadership commitment, dedicated resources, and organizational structure; awareness and common understanding of IPE; open communication; student engagement; and faculty ambassadors as key factors for developing a comprehensive and integrative IPE curriculum (Barnsteiner, Disch, Hall, Mayer, \& Moore, 2007; Bennett et al., 2011; Blue, Mitcham, Smith, Raymond, \& Greenberg, 2010; Djukic, Fulmer, Adams, Lee, \& Triola, 2012; Evans, Cashman, Page, \& Garr, 2011; MacKenzie \& Merritt, 2013). There remains a dearth of evidence informing the bigger challenge of sustainable scale-up within academia and its interdependency with the health services sector. Efforts and research aimed at understanding how higher education institutions 
use an adoption model framework to facilitate the diffusion of IPE within and between organizations and sectors would begin to address this gap in the literature.

The University of Manitoba (UofM) IPE Initiative (the Initiative) chose "IECPCP: An Evolving Framework” (the IECPCP framework) (D’Amour \& Oandasan, 2005) (Figure 1) as the framework to guide the implementation of IPE within its organization, because of its specific emphasis on IECPCP and because it was the framework recommended by researchers for the 2005-2008 Health Canada-funded IECPCP projects (Oandasan et al., 2004). Based on organizational theory and organizational sociology, the framework identifies two interdependent components: (i) interprofessional education and (ii) collaborative personcentred care. Guided by this framework, the Initiative was able to prospectively and purposefully identify and address education and socialization factors at the micro level as well as influence change in structures and processes within the institution (meso-factors) and within and between academia, practice environments, government, and regulatory systems (macro-factors) to develop and implement sustainable and theoretically grounded interprofessional (IP) learning opportunities. The framework underscores the importance of using a systems approach to advance IECPCP, emphasizing that interventions occurring at any single level will likely not lead to sustainable change. Simultaneous engagement and change at all levels are required (D'Amour \& Oandasan, 2005). The interdependency between the education and health service delivery systems is a critical component of the framework, requiring all sectors to embrace and advance the ideals of collaboration in parallel.
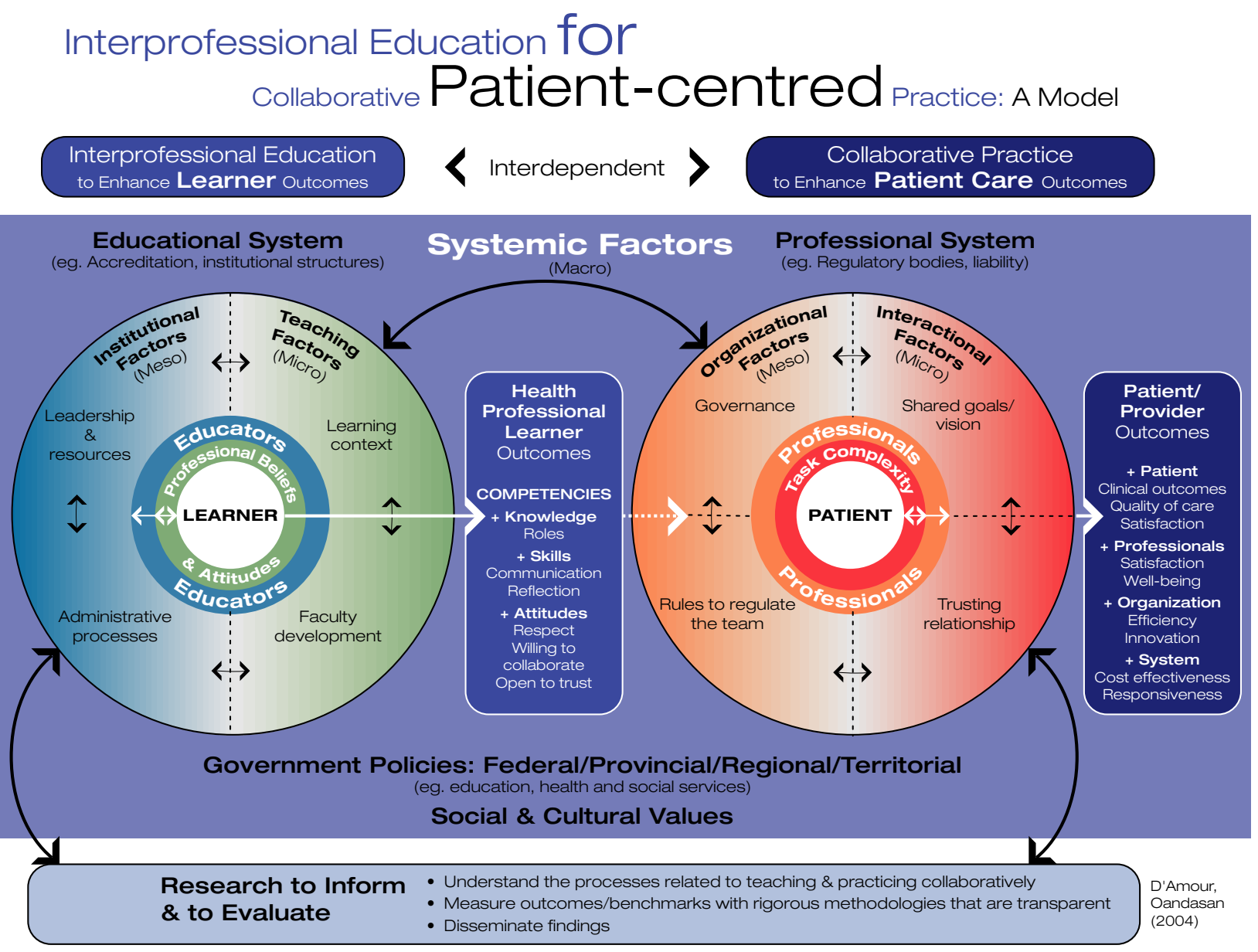

Figure 1. IECPCP evolving framework. (From D'Amour and Oandaan [2005]. Copyright 2005 by D’Amour. Reprinted with permission.) 


\section{Implementation of IPE at the University of Manitoba}

The IECPCP framework (D'Amour \& Oandasan, 2005) served as a road map to help the Initiative anticipate and address the complex factors within the broader context of education and health service delivery that enabled the spread and promoted the sustainability of IPE within the UofM. Viewed through the IECPCP framework, the Initiative reached several milestones but also encountered a variety of challenges. We offer our recommendations based on what worked well; we also share our lessons learned when challenges were encountered. These points are summarized in Table 1.

Table 1.

Advancing IECPCP within the educational system: Levels of influence

Macro

Partnership with government and practice communities

Accreditation as a driver for IPE

Research and scholarly works

Evaluation and quality improvement

Meso

Leadership support

Organizational structure

IPE coordinator

Dedicated resources

Strategic plan

Micro

Common frameworks and language

Educational theory to inform interprofessional learning opportunities

Interprofessional planning for IPE

Faculty development

A Collaborative Competency Learning Continuum

Engaging students

Attending to the complexities of IP communication

Developing strategies to minimize inertia

\section{Macro-Level Factors}

These comprise influences and decisions made by government (including education, health, and social policies) and profession-specific policies (including regulatory and accrediting organizations). Recommendations are as follows.

Create partnerships with government, professional regulatory colleges, and practice communities. Actualizing partnerships between the higher education institutions, practice (health authorities, healthcare delivery settings), government, and regulatory sectors requires the active engagement and commitment of identified IPE ambassadors within each sector (Barr \& Ross, 2006). One example of a collaboration that worked particularly well for the Initiative was our partnership with the Winnipeg Regional Health Authority (the Region). The Region is the major governing organization responsible for 
providing health care to the city of Winnipeg (approximately 700,000 people), the surrounding regions of East and West St. Paul, and the northern Manitoba town of Churchill. In addition, the Region also helps to provide health care to 500,000 Canadians-including individuals in Ontario and Nunavut-who live outside its boundaries but are part of a service partnership within those areas (Winnipeg Regional Health Authority, 2015). This partnership was fostered through ensuring reciprocal representation on key IECPCP leadership committees, joint presentations about IECPCP at senior management committees within both organizations, shared responsibility for developing, implementing, and evaluating IP education and collaborative care innovations, and assuming shared responsibility in faculty development (including health service delivery workers). Our partnership with the Region was further strengthened by collaborative efforts in conducting demonstration and research projects. Securing seed funding from the Manitoba Ministries of Health and Education to support IPE innovation served as a mechanism for the Initiative to partner with our provincial ministries, with the added advantage of synergizing the advancement of knowledge and facilitating knowledge translation in IECPCP at this macro level. As the IECPCP framework suggests, parallel movement towards IECPCP across all sectors is critical, so these collaborations and partnerships were an early priority for the Initiative.

Use accreditation and educational outcomes as leverage for change and self-reflection. Accreditation of education programs is proposed as one potential mechanism for assuring that attention is paid to IECPCP during pre-licensure professional programs. In Canada, the Accreditation of Interprofessional Health Education (AIPHE) project, originally involving the eight accrediting organizations of six health professions, is having a growing influence on the integration of IPE standards, criteria, and evidence into professional education accreditation processes (Accreditation of Interprofessional Health Education, 2009). Although not all health professional programs have specifically articulated accreditation standards for IPE, most make indirect reference by specifying the need for students to learn to communicate with others as part of their professional responsibilities (Curran, Fleet, \& Deacon, 2006).

Thus, IPE ambassadors used accreditation as one strategy to accelerate the IECPCP movement and to drive change. As an example, in the early days of IPE at the UofM, the deans and department heads of the 13 academic units participating in the Initiative had a lengthy debate regarding what constitutes IPE and what does not. Sharing with the deans how AIPHE defined IPE provided sufficient evidence to end the debate and accelerate consensus around the terminology, which, in turn, supported the development of IP learning opportunities meeting these criteria.

Accreditation standards also help education institutions identify areas where further development may be needed. For example, a second AIPHE publication has outlined where and how accrediting organizations may facilitate uptake of IPE within the programs they accredit. The document suggested language for embedding IPE standards into such domains as institutional commitment, academic program, students, faculty, and/ or resources (Accreditation of Interprofessional Health Education, 2012). Similarly, the Institute of Medicine, Lancet Commission Report underscored the significant role that accreditation plays in changing health professions' education in general and made specific reference to the importance of aligning accreditation standards with healthcare reform and priorities for social accountability (Frenk et al., 2010). Specifically, the Lancet 
Commission recommended "stewardship mechanisms, including socially accountable accreditation" (p. 1925), as one of several multilevel enabling actions to achieve transformative learning. One of the largest IP learning opportunities at the UofM focuses on social determinants of health and was piloted by a social work faculty IPE ambassador.

Profession-specific educational outcomes also guide curriculum planning. Several health professional programs and regulatory authorities (including in medicine, pharmacy, physical therapy, occupational therapy, registered nursing, licensed practical nursing, dental hygiene, and dentistry) have included "collaborator" in their entry-to-practice educational outcomes and as examinable content in the licensing exams. Further, many of these entities have revised their criteria to align with the Canadian Interprofessional Health Collaborative (CIHC) National Interprofessional Competency Framework (CIHC, 2010; Frank, Snell, \& Sherbino, 2015). This more explicit mention of IP collaboration has the potential to accelerate change within those programs guided by a learning continuum and educational outcomes framework.

Develop a research and evaluation strategy to address anticipated challenges. Research and evaluation are important macro-determinants of sustainability, as they further our understanding of IECPCP, improve the quality of teaching and collaborative practice, and provide evidence of the impact of IECPCP on learner and patient outcomes (D'Amour \& Oandasan, 2005). A rigorous and systematized program evaluation may be ideal; however, this can be resource-intensive, and the timing must be carefully considered. The Initiative has adopted a philosophy of continuous quality improvement. All of the IP learning opportunities offered through the Initiative were evaluated, with results and recommendations fed back to the relevant working groups for their consideration and potential improvement of the IP learning opportunity. Reports on each IP learning opportunity offering were written and posted on a public Initiative website for dissemination. Dissemination of these reports to the deans and the Vice President (Academic) served the dual purpose of providing accountability and justifying the budget.

Recognizing the importance of research and evaluation, the Initiative supported IPE ambassadors to pursue scholarship in IECPCP through a modest offering of travel grant awards, research technician support, and letters of recognition. Further realization of this priority proved to be complex. The Initiative identified the need to develop a research strategy that outlined infrastructure, resources, and policies and procedures to support research in IECPCP. The Initiative fostered interprofessional dialogue to ensure professional differences in research language, cultures, and values were recognized and considered in the design of the research strategy. Although many IPE ambassadors are collaborating in IECPCP research and evaluation, consensus on a formalized research strategy has yet to be realized. Key issues that have been discussed include the importance of fair processes for allocating shared resources (e.g., travel money, research technician support), opportunities for mentorship and collaboration around grant application and the publication of findings, the roles and responsibilities of principal and co-investigators, as well as the level of contribution that warrants authorship on joint projects.

\section{Meso-Level Factors}

These refer to institution and organization structures and processes and their respective leaders and ambassadors that enable the advancement of IECPCP. Recommendations include the following. 
Create an organizational structure. Sustainable development and implementation of IPE requires institutional commitment (D'Amour \& Oandasan, 2005; Oandasan \& Reeves, 2005b). Figure 2 depicts the organizational structure of the UofM IPE Initiative 2008-2015. Support from senior administrators was a critical enabler, as these individuals have responsibility for decisions relevant to educational policy, resource allocation, curriculum change, and identification and support of faculty ambassadors (Freeth, 2001; Parsell \& Bligh, 1998; Pirrie, Wilson, Harden, \& Elsegood, 1998). At the UofM, the deans and department heads of 13 academic units agreed to support a centralized office of IPE, including the secondment of an IPE Coordinator and the allocation of dedicated resources for administrative support and operating funds. In addition to responsibilities for the overall day-to-day activities of the Initiative, the IPE Coordinator was responsible for overseeing the planning of IP learning opportunities, sharing the lead in advancing and disseminating scholarly works and program evaluation, and participating in local, national, and international networks. The original organizational structure for the UofM Initiative (http://umanitoba.ca/programs/interprofessional/) was established with the IPE Coordinator answering directly to the Vice President (Academic) and Provost. This senior-level line of accountability was advantageous, as it gave the Initiative credibility both within and external to the University of Manitoba. Having the Initiative not be formally affiliated with any particular academic unit was deliberate. An IPE steering committee, comprised of the deans/department heads of the 13 participating academic units and chaired by the VP (Academic), served as the decision-making body. The IPE Coordinator was supported by an IPE Liaison Advisory Committee with faculty representation from each participating academic unit, its primary practice partner (the Region), and a student representative. The roles of the IPE ambassadors on the liaison committee were essential and included serving in an advisory capacity, overseeing IPE curriculum implementation, providing leadership for IPE within their respective academic units, and facilitating communications between the Initiative and the academic units. This organizational structure served as an important mechanism for ensuring roles and responsibilities and lines of communication were clear and activities within the Initiative were coordinated and strategic, while allowing for comprehensive and transparent communication.

The accountability of the IPE coordinator changed from the VP's Office to the Chair of the IPE Steering Committee, one of the deans of the 13 academic units. This change in line of accountability posed challenges for the Initiative, as the Chair was a rotating position. In 2014-2015, 10 of the 13 academic units participating within the Initiative amalgamated to create a new Faculty of Health Sciences. The Faculty of Health Sciences includes a College of Medicine (Medicine, Physician Assistant, Clinical Health Psychology) and Colleges of Nursing, Pharmacy, Dentistry (Dentistry, Dental Hygiene), and Rehabilitative Sciences (Occupational Therapy, Physical Therapy, and Respiratory Therapy). The legacy of the Initiative was sustained, as IPE was identified as one of seven priority themes for the Faculty of Health Sciences, despite a time of significant fiscal restraint and cutbacks. This restructuring will require new systems for support, resource allocation, and organizational structure to maintain and build on the strength of the former Initiative as well as the inclusivity of the other academic units, such as Kinesiology and Recreation Management, and Social Work. 


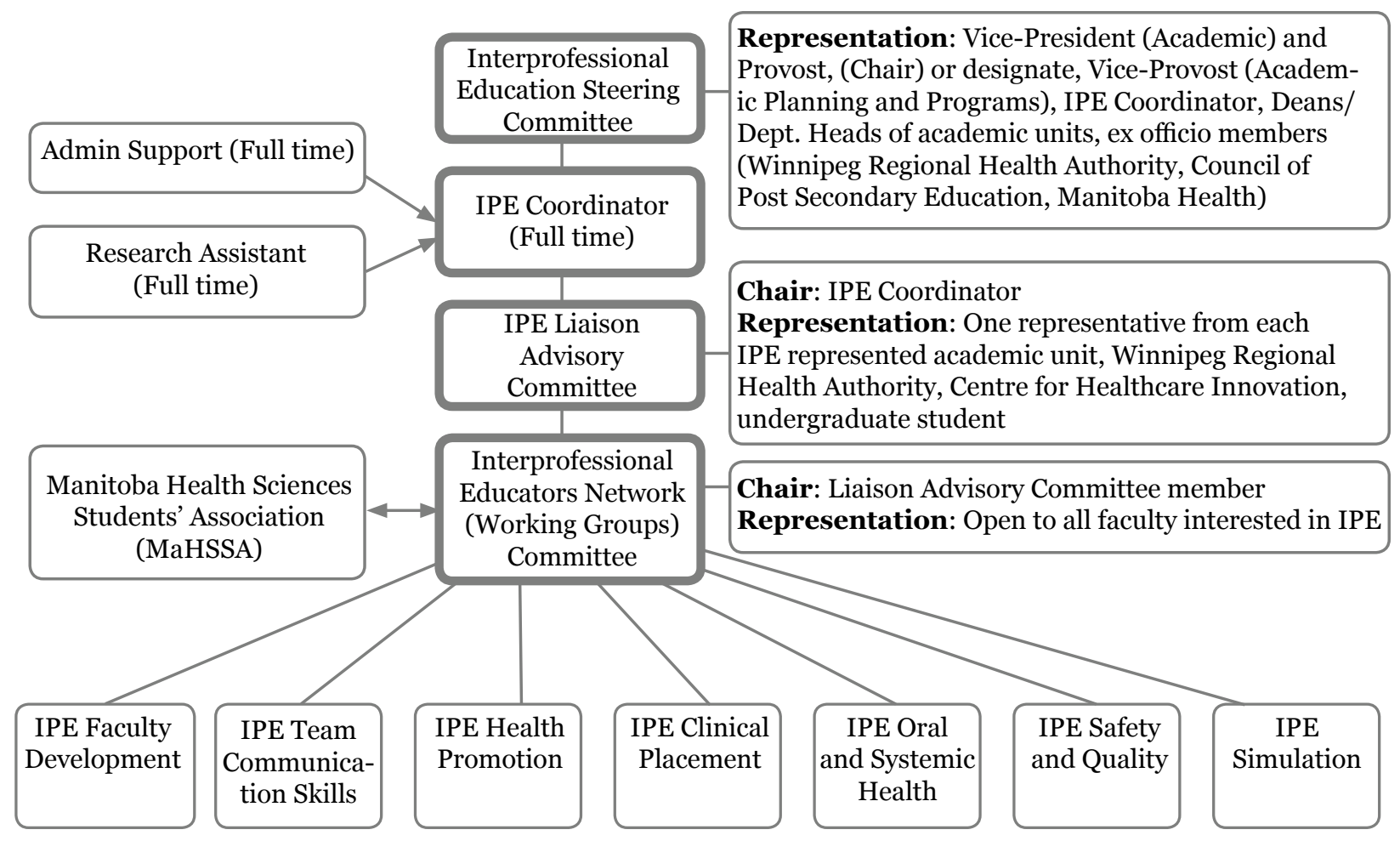

Figure 2. UofM IPE Initiative organizational structure.

Take the time to develop, revisit, and revise a strategic plan. At the outset, the Initiative developed a strategic plan for IPE, outlining the vision, mission, working definitions, strategic priorities, benchmarks, and timelines. The process of developing the strategic plan has allowed the participants to reach consensus on issues related to IECPCP. In contrast to the "top-down" approach noted by curriculum developers in United Kingdom Higher Education Institutions (Craddock, O’Halloran, McPherson, Hean, \& Hammick, 2013), the Initiative's organizational structure promoted a "top-down, bottomup, and lateral" approach to strategic planning. The UofM Initiative's Guiding Principles (available on the Initiative website), developed as part of the strategic planning process, were noteworthy, as they set the foundation for planning activities within the Initiative.

The process of developing a strategic plan takes time, effort, and expertise. The Initiative held several half-day retreats involving senior administrators and IPE ambassadors to develop and finalize the plan. The Initiative used the strategic plan for accountability and benchmarking.

\section{Micro-Level Factors}

These refer to education and socialization factors that may either enable or impede acceptance and uptake of IECPCP, such as the professional cultural values of healthcare providers, educators, and learners. It requires consideration of what to teach, to whom, how, when, where, and by whom (D'Amour \& Oandasan, 2005; Oandasan \& Reeves, 2005a). Further, the micro-level factors remind us that interprofessional collaboration is essential in the diffusion of IPE innovation and that shared goals and leadership facilitate the ability to solve complex problems with depth and breadth. Recommendations include the following. 
Adopt common frameworks and language. When planning for IPE, it was noted that health professionals use different terminology to describe a person or a healthcare activity. For example, some healthcare professionals describe "providing health care to patients" while others "offer support and services to clients." To facilitate IPE across academic programs, one of the guiding principles developed by the Initiative included the importance of adopting inclusive terminology while at the same time respecting entrenched professional differences. In an effort to harmonize language, reduce confusion, and avoid misunderstanding between the academic and practice sectors, the Initiative and the Region jointly endorsed the CIHC National Interprofessional Competency Framework outlining six competency domains as the desired behaviours of a collaborative practitioner (CIHC, 2010). The Initiative and the Region also adopted and operationalized the CAIPE definition of IPE: "occasions when two or more professions learn with, from and about each other to improve collaboration and the quality of care" (CAIPE, 2002). The goal of IPE is to engage students in interactive learning that will enhance their interprofessional collaborative competencies and effect positive health outcomes for patients (Accreditation of Interprofessional Health Education, 2009).

Use educational theory to inform the development of interprofessional learning opportunities. By definition, IPE is grounded in educational theory, including adult learning theory (Knowles, 1980), case-based learning (Woodhouse \& Pengally, 1992), small group learning (Gill \& Ling, 1995), cooperative learning (D’Eon, 2004), and IPE principles (Accreditation of Interprofessional Health Education, 2009). The Initiative adopted the Points for Interprofessional Education (PIPES) instrument (Wagner, Langlois, Lowe, \& Simmons, 2009) as a quantitative tool to measure the degree to which IP learning opportunities are consistent with these theories and principles. IP learning opportunities that are case-based, facilitated, offer opportunities to debrief, involve small and interactive groups of learners, and are relevant to real practice receive high scores on the PIPES. Within the Initiative, the PIPES gained recognition as a "real-time" quality improvement tool providing a quick way for session planners to determine to what extent their IP learning opportunities met these attributes of IPE.

Encourage IP planning for IPE. The Initiative relied heavily on IP working groups as an effective and efficient way to develop and implement IP learning opportunities. IP working groups were established with strategic priorities, and the available expertise, interest, time, and resources of faculty. The concept of IP working groups encourages faculty with expertise in a "learning commons" (also known as "vectors," such as safety and quality, social determinants of health, ethics, falls prevention, etc.) to offer a perspective through their professional lenses. When the working group members were the course instructors responsible for the learning commons, there was the added advantage that they could address many of the logistical issues that arose when embedding the IP learning opportunities within their respective courses.

All IP working groups within the Initiative developed terms of reference with some uniformity across working groups to understand their responsibilities while holding true to the guiding principles and definitions outlined in the strategic plan. The working groups met monthly and recorded minutes for transparency purposes.

Make faculty development a priority. Educators must possess the necessary knowledge, skills, behaviours, and attitudes in IECPCP in order to be able to teach ef- 
fectively (D'Amour \& Oandasan, 2005). Just as the process of socialization is key to IP learning for students, it is equally important that health educators "walk the talk" and adapt their teaching approaches accordingly (Freeth, 2001; Parsell \& Bligh, 1998). IP learning is different from uniprofessional learning in several ways. Teamwork skills must be taught; learners must have opportunities to learn about, with, and from each other; and educators must be prepared to address any overt or hidden stereotyping, hierarchies, and power struggles that may occur during interprofessional interactions. IPE facilitators require skills to identify, support, and comment on group process and to assess student interprofessional competencies.

The Initiative established an IP Faculty Development Working Group to create and implement an IP faculty development curriculum. This working group developed a threehour introductory level workshop entitled "Introduction to IPE," recommended for all faculty within the 13 participating academic units. Over time, the vast majority of UofM faculty within many of the smaller academic units had participated, and the Initiative invited front-line staff and managers from the practice community to participate as a form of IP continuing professional development. In addition to fostering inter-sectoral partnerships, this IP continuing professional development strategy built collaborative care capacity and expertise and encouraged clinician involvement in practice and nonpractice IPE opportunities. Both quantitative and qualitative evaluation resulting from the "Introduction to IPE" workshop demonstrated positive outcomes (Ateah et al., 2011). A more advanced three-hour "How to Facilitate IPE" workshop was tailored specifically to prepare faculty to facilitate a small group IP learning opportunity, titled "Learning Health Promotion Interprofessionally." For faculty who had previously facilitated an IP learning opportunity but wanted a "refresher" and were seeking opportunities for information exchange to share challenges and strategies, the IPE Initiative offered one-hour informal "brown-bag" sessions to facilitate these discussions.

Develop an IP collaborative competency learning continuum. There are varying opinions regarding the ideal time in a student's continuum of learning when health professionals should be "socialized" in providing IP collaborative care competencies (Borduas et al., 2006). The Initiative advocated for an IPE curriculum with IP collaborative care competencies recognized as desired observable and measurable outcomes for graduates from all participating health professional programs within the Initiative (Thistlethwaite \& Moran, 2010). The development of collaborative competency requires the advancement of knowledge, attitudes, skills, and behaviours, as well as group relationship abilities along a continuum of learning within a purposely "scaffolded" curriculum of increasing complexity and varying contexts, environments, and knowledge (D’Eon, 2005). A Collaborative Competency Learning Continuum (available on the Initiative website) was developed as an adaptation of the UofM University Teaching Services model Teaching for Excellence: The Development of Expertise and includes five stages in the development of expertise (novice, functional, competent, proficient, expert) (Kristjanson, 2010) in the six CIHC collaborative competencies (CIHC, 2010). The framework is multidimensional and incorporates the influences of organizational culture and context within the UofM and the Region on the development of expertise. The learning continuum ensures that our approach to IECPCP between academia and practice is consistent and strategic and that it provides a framework for student assessment and program evaluation. 
Encourage student engagement in all aspects of IPE. As students were future healthcare providers and change agents, their engagement was critical to the advancement of IECPCP and was a priority within the Initiative. This proved to be challenging. We experienced a paradox whereby students were enthusiastic about volunteering in IECPCP activities such as student-run clinics, simulation events, the Health Care Team Challenge, and the Institute for Healthcare Improvement Open School, but meaningful and sustainable commitment at an administrative level to include student involvement in working groups was difficult. Some of the reasons were their rapid turnover and limited availability for weekday meetings. In Canada, the National Health Sciences Students' Association (NaHSSA) is a student organization that advocates for IECPCP nationally. The Manitoba Health Sciences Student Association (MaHSSA) is one of 19 Canadian chapters of NaHSSA with a local mandate. MaHSSA has the potential to provide a centralized mechanism for engaging student participation in Initiative activities. Whereas the volunteer IECPCP activities have tremendous financial, faculty, and institutional support, MaHSSA has not been formally supported by the Initiative. The Initiative has responded by seeking and obtaining a mechanism for students to be formally acknowledged for their involvement in all not-forcredit IECPCP activities. However, more support for MaHSSA is required.

Attend to the complexities of communication. Despite the Initiative's organizational structure, communications within and between organizations posed challenges. To address the complexities of communication, the Initiative encouraged regular face-toface meetings, conference calls, and regular email correspondence. Unfortunately, even when a communication structure, a plan, and a feedback mechanism exist, communication gaps occur, causing communication breakdowns and setbacks. At the interactional level, the interprofessional approach to planning curricular change required members of the initiative from different professions to work closely together. This collaboration offered an opportunity to model the competencies we hoped to instil in our students (see Figure 3). It is important to facilitate interprofessional team communication and incorporate conflict management processes between IPE ambassadors to foster the growth of any IPE culture shift.

Develop strategies to minimize inertia. The Initiative benefitted from the strong commitment of IPE leaders and ambassadors and the coordinated efforts in implementing IPE. The Initiative succeeded overall in developing strong relationships between all levels of participants as well as trust and respect within its networks. Clark (2013) labeled this "partnership capital," which helps initiatives through times of budget cuts and changing administrators (p. 46).

That being said, IPE at the UofM continues to be vulnerable and subject to inertia. Turnover in leadership within government, the university, and the practice environments poses challenges for maintaining institutional awareness, commitment, and partnerships. A strong sense of interprofessional team identity is important for team effectiveness (Mitchell, Parker, \& Gillis, 2011), and frequent changes in group membership can have a detrimental effect upon momentum towards IECPCP. An important lesson here is that the strategic planning process should include discussions around strategies to minimize inertia, address turnover, provide incentives, build human capacity, attract resources, and minimize redundancies within academic institutions. 
Sustainable Implementation of Interprofessional Education / R. E. Grymonpre, C. A. Ateah, H. J. Dean, T. I. Heinonen, M. E. Holmqvist, L. L. MacDonald, A. E. Ready, \& P. F. Wener

CIHC Competencies (CIHC 2010) Descriptors of Competencies (CIHC 2010) As Evidenced by UofM IPE

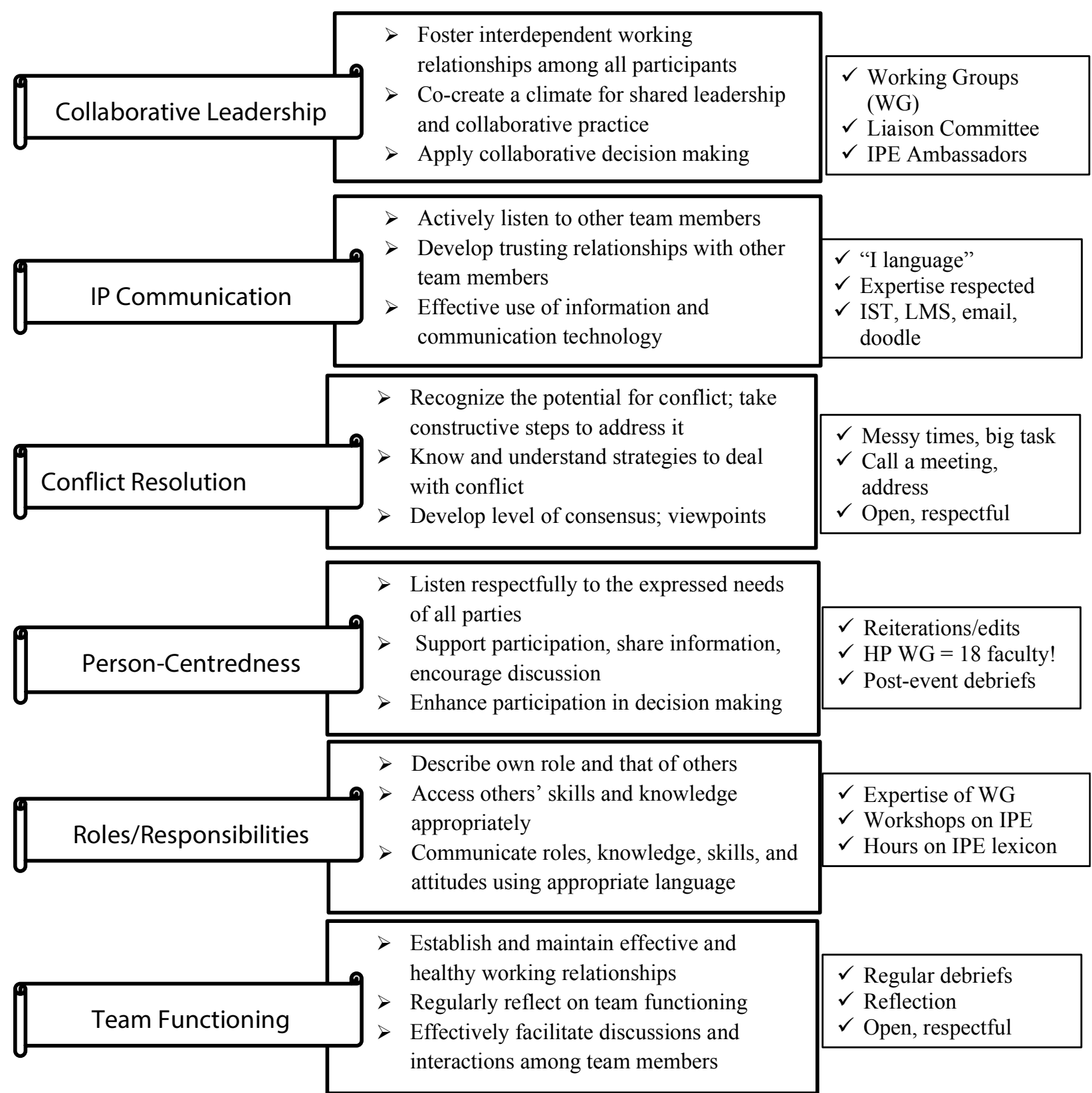

Figure 3. Canadian Interprofessional Health Collaborative (CIHC) collaborative competencies in action. 


\section{Discussion and Conclusion}

The key message of this paper is that there is value in using an adoption model framework to guide implementation, sustainability, and scale-up of IPE within a higher education institution. The impact of these strategies implemented at the UofM is outlined in a separate manuscript, wherein we report on a longitudinal analysis of improvements seen in the number and attributes of IP learning opportunities offered at the UofM between 2009 and 2012 (Grymonpre et al., 2016).

There is every indication that IPE within the University of Manitoba will be sustained and continue to grow. Despite a significant transition within the UofM from four faculties (Dentistry, Medicine, Nursing, Pharmacy) to one Faculty of Health Sciences and five colleges (Dentistry, Medicine, Nursing, Pharmacy, and Rehabilitation Sciences), IPE remains integral to the revised organizational structure, with increased resources allocated. At the macro level, intersectoral partnerships remain strong, collaborative competencies are a mandatory component of assessment for most participating professional bodies, and many accrediting organizations are looking for evidence of IPE in their program reviews. At the meso level, institutional reorganization has reemphasized IPE, and several IP learning opportunities are now embedded within shared curricula, with new opportunities being developed all the time. At the micro level, we see evidence that a shared understanding of IPE has developed, with a majority of faculty in most academic units completing some IPE training, and we see increasing evidence that IPE is valued by our practice colleagues and our community.

This report builds on a recent literature review citing the barriers and enablers to embedding IPE within postsecondary education institutions at the government, professional, institutional, and individual stakeholder levels (Lawlis, Anson, \& Greenfield, 2014). In their study, Lawlis and colleagues noted a dearth of evidence linking key elements of sustainability to macro-, meso-, and micro-stakeholder levels, and further, a lack of evidence linking these key elements to actual IPE sustainability. Our paper addresses both of these gaps in the IPE literature. Lawlis et al. also cited examples of the same element being identified as a barrier in some studies and an enabler in others. Our paper suggests that use of an adoption model framework facilitates a proactive, strategic, and comprehensive approach, favouring enabling as opposed to disabling relationships and outcomes.

Although there has been growth in the diffusion of innovation or adoption model frameworks that are relevant to IECPCP, the D'Amour and Oandasan (2005) framework worked well for the UofM Initiative. We encourage others to consider this framework, as use of a common framework has the added advantage of facilitating comparisons across IPE initiatives. Despite the many advantages, it is important to acknowledge that frameworks do not unveil all challenges encountered at the macro, meso, and micro levels. Legislative, administrative, fiscal, or interpersonal realities and frameworks and theories must evolve to better capture the unique realities of implementation. This paper describes one institution's experience in implementing a sustainable program of IPE. We encourage others to share their experiences as well.

\section{Acknowledgement}

The authors would like to acknowledge Achini Weeraratne for her technical support in the preparation of this manuscript. 


\section{References}

Accreditation of Interprofessional Health Education. (2009). Accreditation of interprofessional health education (AIPHE) principles and practices for integrating interprofessional education into the accreditation standards for six health professions in Canada. Retrieved from: http://casn.ca/wp-content/uploads/2014/12/AIPHEPrinciples andPracticesGuidev2EN.pdf

Accreditation of Interprofessional Health Education. (2012). Interprofessional health education accreditation standards guide: Phase 2. Retrieved from: http://www. cihc.ca/files/resources/public/English/AIPHE\%2OInterprofessional\%20Health\%20 Education\%20Accreditation\%20Standards\%20Guide_EN.pdf

Ateah, C. A., MacDonald, L., Amara, F., Dean, H., Fricke, M., Grymonpre, R., . . . Weinberg, L. (2011, November). Developing a process for faculty development in interprofessional education: The University of Manitoba experience. Poster presentation at Collaborating Across Borders Conference III, Tucson, AZ.

Barnsteiner, J. H., Disch, J. M., Hall, L., Mayer, D., \& Moore, S. M. (2007). Promoting interprofessional education. Nursing Outlook, 55, 144-150.

Barr, H., \& Ross, F. (2006). Mainstreaming interprofessional education in the United Kingdom: A position paper. Journal of Interprofessional Care, 22, 96-104.

Bennett, P. N., Gum, L., Lindeman, I., Lawn, S., McAllister, S., Richards, J., . . Ward, H. (2011). Faculty perceptions of interprofessional education. Nurse Education Today, $31,571-576$.

Blue, A., Mitcham, M., Smith, T., Raymond, J., \& Greenberg, R. (2010). Changing the future of health professions: Embedding interprofessional education within an academic health center. Academic Medicine, 85, 1290-1295.

Borduas, F., Frank, B., Hall, P., Handfield-Jones, R., Hardwick, D., Ho, K., . . Wright, B. (2006). Facilitating the integration of interprofessional education into quality health care: Strategic roles of academic institutions. Retrieved from http://www.cihc.ca/files/ complementary/2006-10-31\%20AICC_Facilitating\%20IPE_Finalpdf.pdf

Canadian Interprofessional Health Collaborative [CIHC]. (2010). A national interprofessional competency framework. Retrieved from http://www.cihc.ca/files/ CIHC_IPCompetencies_Feb1210.pdf

Centre for the Advancement of Interprofessional Education [CAIPE]. (2002). The definition and principles of interprofessional education. Retrieved from http://caipe. org.uk/about-us/the-definition-and-principles-of-interprofessional-education/

Clark, P. G. (2013). Toward a transtheoretical model of interprofessional education: Stages, processes and forces supporting institutional change. Journal of Interprofessional Care, 27, 43-49.

Craddock, D., O’Halloran, C., McPherson, K., Hean, S., \& Hammick, M. (2013). A top-down approach impedes the use of theory? Interprofessional educational leaders' approaches to curriculum development and the use of learning theory. Journal of Interprofessional Care, 27, 65-72. 
Curran, V., Deacon, D., \& Fleet, L. (2005). Review, assessment and recommendations of accreditation standards, policies, and practices as they relate to interprofessional education for collaborative patient-centered practice (IECPCP). Ottawa, ON: Health Canada.

Curran, V., Fleet, L., \& Deacon, D. (2006). A comparative review of Canadian health professional education accreditation systems. Canadian Journal of Higher Education, $36,86-87$.

D'Amour, D., \& Oandansan, I. (2005). Interprofessionality as the field of interprofessional practice and interprofessional education: An emerging concept. Journal of Interprofessional Care, 19(S1), 8-20.

D’Eon, M. (2004). Interdisciplinary learning: Principles and methods. Ottawa, ON: Health Canada.

D’Eon, M.(2005). Blueprintfor interprofessionallearning.JournalofInterprofessional Care, 19, 49-59.

Djukic, M., Fulmer, T., Adams, J. G., Lee, S., \& Triola, M. M. (2012). NYU3T: Teaching, technology, teamwork: A model for interprofessional education scalability and sustainability. Nursing Clinics of North America, 47, 333-346.

Evans, C. H., Cashman, S. B., Page, D. A., \& Garr, D. R. (2011). Model approaches for advancing interprofessional prevention education. American Journal of Preventive Medicine, 40, 245-260.

Frank, J. R., Snell, L., \& Sherbino, J. (2015). The draft CanMEDS 2015 Physician Competency Framework-Series IV. Ottawa, ON: Royal College of Physicians and Surgeons of Canada.

Freeth, D. (2001). Sustaining interprofessional collaboration. Journal of Interprofessional Care, 15, 37-46.

Frenk, J., Chen, L., Bhutta, Z. A., Cohen, J., Crisp, N., Evans, T., .. . Zurayk, H. (2010). Health professionals for a new century: Transforming education to strengthen health systems in an interdependent world. The Lancet, 376, 1923-1958.

Gill, J., \& Ling, J. (1995). Interprofessional shared learning: A curriculum for collaboration. In K. Soothill, L. Mackay, \& C. Webb (Eds.), Interprofessional relations in health care. London, UK: Edward Arnold.

Greenhalgh, T., Robert, G., Macfarlane, F., Bate, P., \& Kyriakidou, O. (2004). Diffusion of innovations in service organizations: Systematic review and recommendations. Milbank Quarterly, 82, 581-629.

Grymonpre, R., Dean, H., James, M., Wener, P., Ready, A. E., MacDonald, L., . . Fricke, M. (2016). Quantifying interprofessional learning in health professional programs: The University of Manitoba experience. Canadian Journal of Higher Education.

Knowles, M. (1980). The modern practice of adult education-from pedagogy to androgogy. Chicago, IL: Follett Publishing. 
Kristjanson, C. (2010). Teaching for excellence: The development of expertise. Path to Pedagogy, 18(2). Retrieved from http://intranet.umanitoba.ca/academic_support/catl/ media/Winter_09_Path_to_Pedagogy_Volume_18.pdf

Lawlis, T. R., Anson, J., \& Greenfield, D. (2014). Barriers and enablers that influence sustainable interprofessional education: A literature review. Journal of Interprofessional Care, 28, 305-310.

MacKenzie, D., \& Merritt, B. K. (2013). Making space: Integrating meaningful interprofessional experiences into an existing curriculum. Journal of Interprofessional Care, 27, 274-276.

Mitchell, R. J., Parker, V., \& Giles, M. (2011). When do interprofessional teams succeed? Investigating the moderating roles of team and professional identity in interprofessional effectiveness. Human Relations, 64, 1321-1343.

Oandasan, I., D’Amour, D., Zwarenstein, M., Barker, K., Purden, M., Beaulieu, M. D., \& Tregunno, D. (2004). Interdisciplinary education for collaborative, patient-centred practice: Research and findings report. Ottawa, ON: Health Canada.

Oandasan, I., \& Reeves, S. (2005a). Key elements for interprofessional education, Part 1: The learner, the educator, and the learning context. Journal of Interprofessional Care, $19(\mathrm{~S} 1), 21-38$.

Oandasan, I., \& Reeves, S. (2005b). Key elements for interprofessional education, Part 2: Factors, processes and outcomes. Journal of Interprofessional Care, 19(S1), 39-48.

Parsell, G., \& Bligh, J. (1998). Interprofessional learning. Postgraduate Medical Journal, 74, 89-95. doi:10.1136/pgmj.74.868.89

Pirrie, A., Wilson, V., Harden, R. M., \& Elsegood, J. (1998). AMEE Guide No. 12: Multiprofessional education: Part 2-promoting cohesive practice in health care. Medical Teacher, 20, 409-416. doi:10.1080/01421599880481

Thistlethwaite, J., \& Moran, M. (2010). Learning outcomes for interprofessional education (IPE): Literature review and synthesis. Journal of Interprofessional Care, 24, 503-513.

Wagner, S. J., Langlois, S., Lowe, M., \& Simmons, B. (2009, October). Building an interprofessional education curriculum: Core competency and learning activity integration. Paper presented at the Collaborating Across Borders II IPE Conference, Halifax, NS.

Winnipeg Regional Health Authority. (2015, May 21). About us. Retrieved from http:// www.wrha.mb.ca/about/aboutus.php

Woodhouse, D., \& Pengally, P. (1992). Anxiety and the dynamics of collaboration. Aberdeen, Scotland: Aberdeen University Press. 


\section{Contact Information}

Ruby Grymonpre

College of Pharmacy

Rady Faculty of Health Sciences

University of Manitoba

Ruby.Grymonpre@umanitoba.ca

Ruby Grymonpre, BSc (Pharm), PharmD, FCSHP, is a professor, College of Pharmacy, Rady Faculty of Health Sciences, University of Manitoba. Building on over 25 years of experience in "Geriatric Pharmacy," her current scholarly works relate to interprofessional education (IPE) and interprofessional collaborative practice (IPC), with a particular interest in program evaluation, IP practice education, adoption model frameworks, and health human resource outcomes. She served a seven-year term as the IPE coordinator for the $\mathrm{U}$ of $\mathrm{M}$ and as a co-chair for the Accreditation of Interprofessional Health Education project. Most recently, she was appointed to the Board of the Canadian Interprofessional Health Collaborative and the World Coordinating Committee on IPE.

Christine Ateah, Professor, College of Nursing, Rady Faculty of Health Sciences, University of Manitoba, holds a Bachelor of Nursing and an Interdisciplinary PhD from the University of Manitoba, and a Master of Education from the University of Alberta. She is Vice-Dean, Education in the Faculty of Health Sciences, University of Manitoba (U of M), which includes the Office of Interprofessional Collaboration. She served as Interprofessional Education Coordinator in the College of Nursing for three years and has been involved in interprofessional collaboration and education initiatives at the $\mathrm{U}$ of $\mathrm{M}$ for the past decade.

Heather Dean, MD, FRCPC, graduated from Medicine at Queen's University, in Kingston, Ontario, and pursued paediatrics and paediatric endocrinology training in Montréal, Ottawa, and Winnipeg. She was a full-time academic clinician in Winnipeg for 33 years and retired in June 2015 as professor of pediatrics. She held many leadership positions in the Department of Pediatrics and the Faculty of Medicine, University of Manitoba. Her major research areas are type 2 diabetes in children, the transition of adolescents with diabetes to adult care, and interprofessional education. Heather Dean is now retired.

Tuula Heinonen is a professor with the Faculty of Social Work, University of Manitoba. She holds a Doctorate of Philosophy from the Institute of Development Studies, University of Sussex, UK, and a Master of Social Work from McGill University. Her research interests explore social work, health, and well-being; gender in rural China; health dimensions and determinants; arts-informed qualitative research; refugee and immigrant services and needs; international community development; and gender and newcomer settlement in Manitoba.

Maxine Holmqvist received her PhD in clinical psychology from the University of Saskatchewan, where she was a founding member of the Student Wellness Initiative Toward Community Health, a student-run interprofessional health clinic located in a core neigh- 
bourhood of Saskatoon. She is currently an assistant professor and coordinator for interprofessional education in the Department of Clinical Health Psychology, College of Medicine, at the University of Manitoba, where she is the theme lead for health psychology/behavioural medicine in the undergraduate medical curriculum. Maxine Holmqvist teaches and conducts much of her research collaboratively and frequently acts as a mentor for interprofessional student groups.

Laura MacDonald, $\mathrm{RDH}$, Med, $\mathrm{PhD}(\mathrm{c})$ is an associate professor with the School of Dental Hygiene, College of Dentistry, Rady Faculty of Health Sciences, University of Manitoba. She has been involved in the development of an interprofessional education curriculum at the $\mathrm{U}$ of $\mathrm{M}$ and is one of five academics appointed to the Office of Interprofessional Collaboration.

A. Elizabeth Ready is a professor in the Faculty of Kinesiology and Recreation Management and the director of the multi-disciplinary Applied Health Sciences doctoral program, at the University of Manitoba. She obtained her PhD in exercise physiology at the University of Alberta. Her research focuses on the health benefits of physical activity in older adults, the integration of physical activity into the primary healthcare system, and age-friendly communities. Her involvement in curriculum development led to her scholarly interest in interprofessional education and collaborative practice.

Pamela Wener, $\mathrm{PhD}(\mathrm{c})$, OT Reg. (MB), is an associate professor in the Department of Occupational Therapy, College of Rehabilitation Sciences, Rady Faculty of Health Sciences, University of Manitoba. She has been involved in the development of an interprofessional education curriculum at the University of Manitoba and is one of five academics appointed to the Faculty of Health Sciences, Office of Interprofessional Collaboration. She is a doctoral candidate studying interprofessional relationships within collaborative mental health care in primary care settings. 